\title{
Inovação tecnológica em serviços logísticos: análise em um terminal marítimo de armazenagem
}

José Petraglia

Doutor em Administração pela Universidade de São Paulo (USP).Mestre em Administração pela PUC - SP; graduado em engenharia mecânica industrial pela FEI - SBC e em administração de empresas pela UNISANTA. É professor titular de graduação, pós-graduação (stricto sensu, lato sensu e MBA, São Paulo, Brasil petraglia@usp.br

Karen Perrotta de Almeida Prado

Doutora em Administração ,e Professora da Universidade Presbiteriana Mackenzie. São Paulo, Brasil

karen.perrota@mackenzie.br

Luciano Augusto Toledo

Doutor em Administração pela FEA-USP, especialista em marketing de serviços pela FIA-USP. É professor PPI da Univesidade Presbiteriana Mackenzie Universidade de São Paulo, São Paulo, Brasil luciano.toledo@mackenzie.br

\section{Editor Científico: José Edson Lara}

Organização Comitê Científico

Double Blind Review pelo SEER/OJS

Recebido em 09.07.2016

Aprovado em 13.03.2017 


\title{
Resumo
}

O objetivo do artigo é investigar como ocorre a Inovação tecnológica em serviços logísticos em um terminal marítimo de armazenagem. Buscou-se identificar o entendimento de inovação e de que forma a empresa gerencia a interação entre organizações envolvidas no processo de inovação tecnológica. O modelo analítico do estudo é baseado em pesquisas bibliográficas e estudo de caso. $O$ estudo mostra que se obtêm inovações tecnológicas com relevante interação dos clientes e outros atores.

Palavras-Chave: Inovação tecnológica; logística e interação organizacional.

\section{Technological innovation in logistics services: analysis in a storage terminal sea}

\begin{abstract}
The objective of this article is to investigate how technology innovation in logistics services occurs in a maritime storage terminal. We tried to identify the understanding of innovation and how the company manages the interaction between organizations involved in the process of technological innovation. The analytical model of the study is based on bibliographic research and case study. The study shows that accrue technological innovations relevant interaction with customers and other stakeholders.
\end{abstract}

Keywords: Technological innovation; logistics and organizational interaction.

\section{La innovación tecnológica en los servicios de logística: Análisis de almacenamiento en una terminal marítima}

\section{Resumen}

El objetivo de este trabajo es investigar cómo la innovación tecnológica de los servicios logísticos de almacenamiento en una terminal marítima. Hemos tratado de identificar la comprensión de la innovación y cómo la empresa gestiona la interacción entre las organizaciones que participan en el proceso de innovación tecnológica. El modelo analítico del estudio se basa en la literatura de investigación y estudio de casos. El estudio muestra que se obtienen las innovaciones tecnológicas con una interacción significativa de los clientes y otras partes interesadas.

Palabras clave: innovación tecnológica; logística y organización de la interacción. 


\section{Introdução}

Constantes e incontroláveis modificações que ocorrem no ambiente de negócios contemporâneo exigem adaptações e ajustes permanentes em produtos e procedimentos (Drucker, 2011; Hartline \& Ferrell, 1996; Lamb, Hair, \& McDaniel, 2008). Não obstante, vislumbra-se um mundo globalizado e capitaneado por tecnologias emergentes e mudanças de paradigmas. Levados pela revolução provocada nesse ambiente, empresários e organizações têm que constantemente inovar. Sob este aspecto a logística se torna escopo para atender o maior número de clientes nas mais diferentes praças, proporcionando maior número de bens e serviços (Huang, Tzeng, \& Ho, 2011; Zhu \& Godes, 2009).

\subsection{Problema de pesquisa}

Como ocorre a Inovação tecnológica em serviços logísticos em um terminal marítimo de armazenagem?

\subsection{Objetivo geral}

Investigar a inovação tecnológica em serviços logísticos marítimos.

\subsection{Objetivos específicos}

- Entender o modelo de inovação sob a ótica de Hertog (2000);

- Investigar o processo de inovação em um terminal marítimo sob a perspectiva dos serviços logísticos.

\section{Revisão Bibliográfica}

\subsection{Inovação}

A inovação é o uso do novo conhecimento para oferecer um novo produto ou serviço que os clientes desejam e envolve sua invenção e comercialização. Assim, a inovação pode estar na formulação do produto, na embalagem, no processo, nas técnicas de marketing ou no serviço prestado ao cliente, podendo representar a sobrevivência ou liderança de uma empresa e até mesmo alterar os hábitos e 
comportamentos de uma sociedade (Hagedoorn, Lokshin, \& Malo, 2016; Lopes et al., 2016).

A inovação tem vários tipos e pode ser radical ou incremental, de processos, produtos ou serviços. A inovação radical é a construção de um produto/serviço completamente novo, algo que não existe ainda, e, por isso, requer grandes investimentos em pesquisa e desenvolvimento. Suas chances de sucesso são menores, porém com probabilidade de maiores recompensas, por isso proporcionam a competitividade no longo prazo (Hagedoorn, Lokshin, \& Malo, 2016; Lopes et al., 2016).

A inovação incremental corresponde às melhorias de produtos, requer menos esforços em P\&D, por isso costuma ser mais comum e ter recompensas menores e não proporcionam a competitividade no longo prazo. A inovação é uma solução para o crescimento da empresa, uma vez que organizações consideradas inovadoras apresentam um desempenho superior no mercado de ações, com retornos acima da média para os acionistas, sendo um condutor para o progresso econômico e a sobrevivência das empresas (Hagedoorn, Lokshin, \& Malo, 2016; Lopes et al., 2016).

A inovação é necessária para que as empresas se tornem competitivas para a garantia de sua sobrevivência no longo prazo. Os autores complementam que o grande desafio das empresas é identificar fontes de inovação que realmente produzam retornos significativos. Dessa forma, a inovação requer o domínio de recursos físicos e tácitos além de competências essenciais que capacitam o processo de inovação, o que envolve custos, conhecimento e tempo para obter o know how, além da necessidade de promover e manter talentos na empresa. Esses autores destacam que as fontes de inovação podem ser internas e externas à empresa (Hagedoorn, Lokshin \& Malo, 2016; Lopes et al., 2016).

Sendo assim, a cooperação é uma alternativa para as dificuldades que algumas empresas podem ter na busca pela inovação (principalmente pequenas empresas), como complexidade tecnológica, altos custos, riscos e pressões por resultados pelos gastos em P\&D. Tal cooperação é necessária para alavancar recursos, compartilhar riscos, realizar pesquisas e joint ventures (Hagedoorn, Lokshin \& Malo 2016; Lopes et al., 2016).

Muitas empresas falham em obter retornos econômicos no processo de inovação, pois se esquecem de que imitadores acabam beneficiando-se mais com a inovação ao aumentar seus lucros e reduzir os riscos e custos de P\&D, por

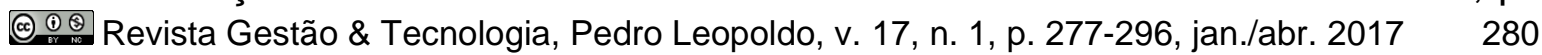


isso, Ciampi et al. (2016), corroboraram a importância da integração e colaboração no processo de inovação

\subsection{Modelo de inovação proposto por Hertog}

Conhecido como modelo quatro dimensionais de inovação em serviços e representado pela Figura 1, serve para construir um entendimento mais profundo do fenômeno da gestão de inovação tecnológica na logística de armazenagem de granéis líquidos. O foco principal do estudo é baseado na dimensão 2 do modelo (Hertog, 2000; Hertog \& Jong, 2007; Rubalcaba, galego \& Hertog, 2010; Hertog, Gallouj \& Segers, 2011).

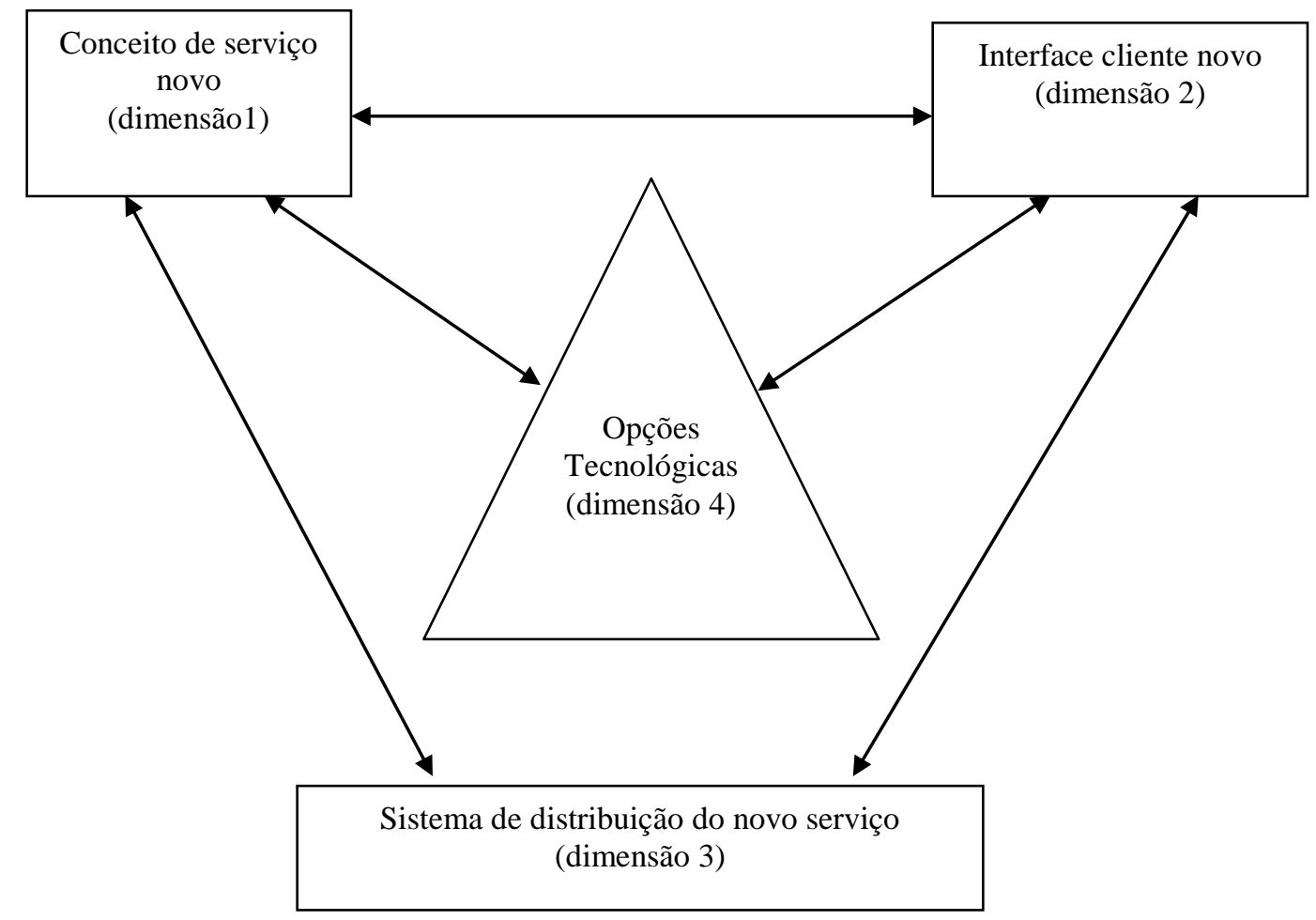

\section{Figura 1}

Modelo quatro dimensionais de inovação em serviços.

Fonte: Hertog, P. D., GallouJ, F., \& Segers, J. (2011). Measuring innovation in a "low-tech" service industry: the case of the Dutch hospitality industry. The Service Industries Journal, 31(9), 1429-1449.

De acordo com Hertog et al. (2011), produzir um serviço é organizar uma solução para um problema o qual não, principalmente, envolve fornecimento de produtos. É locar capacidades e competências (humana, tecnológica, 
organizacional) à disposição do cliente e organizar uma solução, a qual pode ser dada com vários graus de precisão. Os autores ressaltam que um modelo compreensível para entender inovação em serviços, e melhor ainda entender inovação em serviços e outros setores no mesmo framework, não está aparente na literatura. Inovação frequentemente coincide com novos meios de distribuição de produto, interação com cliente e controle de qualidade. Portanto, o modelo quatro dimensionais de inovação em serviços nos permite discutir inovação em termos gerais. A seguir apresentam-se cada uma dessas dimensões, segundo Rubalcaba et al.(2010):

-Dimensão 1: o conceito de serviço - Produtos manufaturados são tipicamente tangíveis e visíveis, diferentemente da maioria dos serviços. Admitidamente, algumas inovações em serviços são altamente visíveis, especialmente onde é envolvido distribuição de produto. Muitos outros envolvem mais características intangíveis.

- Dimensão 2: A interface com o cliente - O segundo elemento de inovação em serviços é o design da interface entre o fornecedor do serviço e os clientes. Essas interfaces são os focos de grandes negócios de inovações em serviços, embora os estudos em inovação, com seu foco em manufatura de massa, tendam a não olhar detalhadamente as mudanças ocorridas nessas interfaces. A maneira como o fornecedor de serviços interage com seus clientes pode, por si próprio, ser uma fonte de inovação.

- Dimensão 3: sistema de distribuição do novo serviço - Essa dimensão, envolvendo distribuição do novo serviço e organização, está frequentemente relacionada diretamente com a dimensão 2 - a ligação entre o fornecedor de serviço e seus clientes. Distribuição é certamente um tipo específico de interação através da interface com o cliente. Entretanto, a dimensão 3 é diferente. Refere-se ao arranjo organizacional interno que tem de ser gerenciado para permitir que os trabalhadores desempenhem seus serviços adequadamente, e para desenvolver e oferecer serviços inovadores. Em outras palavras, novos serviços podem requerer novas formas organizacionais, capacidades e perfis interpessoais.

- Dimensão 4: Opções tecnológicas - A quarta dimensão é o centro de muita análise e debates, especialmente considerando o grau no qual empresas de serviços estão dando formato ao desenvolvimento tecnológico. Claramente, 
inovação em serviço é possível sem inovação tecnológica; tecnologia não é sempre uma dimensão. Porém, na prática, segundo Hertog (2000), há uma larga relação entre tecnologia e inovação em serviços.

Em seu modelo, Hertog et al. (2011) ressaltam que qualquer inovação em serviços envolve alguma combinação das acima mencionadas dimensões de inovação em serviços. E, pode ser a combinação das quatro dimensões que caracteriza cada inovação em serviço particular. $O$ peso de cada dimensão individualmente e a importância das várias ligações entre elas varia de acordo com serviços individuais, empresas e inovações. A geração de inovação tem sido reconhecida como uma consequência de interações entre a empresa e vários atores externos (Ciampi et al., 2016). De acordo com essa visão, o envolvimento dos fornecedores e alianças são rotas de geração de inovação.

\section{Procedimentos Metodológicos}

Orlikowski e Baroudi (1991) lembram que o método do estudo de caso é um dos mecanismos qualitativos comumente utilizados na busca de informações sobre determinado fenômeno. Remeneyi, Money, Price e Bennister (2002) ensinam que o método do estudo de caso pode ser utilizado como um artefato educacional com o propósito de auxiliar os pesquisadores a explorarem e entenderem como se estabelecem determinados fenômenos em algumas empresas, que é o objetivo desse estudo. Eisenhardt (1989) apresenta que uma das singularidades da utilização do método do estudo de caso é a comparação dos resultados levantados com a literatura existente, o que amplia a qualidade do trabalho científico. Nesse processo, tem-se contato com questões relacionadas ao que contradiz, o que é convergente e o porquê. Ainda segundo a autora, no caso da teoria existente ser convergente com a teoria construída, há validação interna e, portanto, há evidências do poder explicativo da teoria. Todavia, na situação em que a teoria existente é divergente da teoria estudada, pode se configurar uma oportunidade para o trabalho explicar o fenômeno de outra forma (Eisenhardt, 1989).

A utilização do método do estudo de caso pode envolver tantas situações de estudo de um único caso, quanto múltiplos casos (Yin, 2005). Frequentemente, o 
problema sob estudo preocupa-se mais em estabelecer as similaridades entre situações e, a partir daí, estabelecer uma base para generalização. A utilização de um único caso é apropriada em algumas circunstâncias: (1) quando se utiliza o caso para se determinar se as proposições de uma teoria são corretas; (2) quando o caso sob estudo é raro ou extremo, ou seja, quando não existem muitas situações semelhantes para que sejam feitos estudos comparativos; ou (3) quando o caso é revelador, ou seja, quando o mesmo permite o acesso a informações não facilmente disponíveis (Yin, 2005). Um estudo de caso também pode envolver a conjugação de casos múltiplos. São exemplos de situações dessa natureza no campo da Administração: o estudo de inovações introduzidas em diferentes áreas de uma empresa, em que cada área é tratada como um único caso; comparação de estratégias operacionais entre diferentes fábricas do mesmo ramo (Stake, 1995), entre outras.

Para o presente trabalho optou-se pela utilização do método do estudo de caso único, com o propósito de se estudar a inovação tecnológica nos serviços de armazenagem de granéis líquidos e a importância da interação dos atores logísticos na geração de inovação. Collis e Hussey (2005) lembram que a utilização do método do estudo de caso exclui a necessidade de se definir universo e amostra a serem estudadas. Portanto, para o desenvolvimento do estudo de caso único utilizado nesta pesquisa, utilizaram-se como unidade de análise as práticas e as percepções relacionadas à inovação tecnológica na empresa de armazenagem de granéis líquidos, a qual chamaremos de "Beta Ltda.", com ampla atuação no setor e facilidade de acesso ao pesquisador. Para o estudo de caso único adotado neste trabalho, foram utilizadas, além da análise documental, a observação do pesquisador e a entrevista semiestruturada. Segundo Triviños (1987), o processo de entrevista semiestruturada dá melhores resultados ao se trabalhar com diferentes grupos de pessoas. O instrumento utilizado para coleta de dados foi um roteiro seguido de entrevista, com questões abertas, considerada como investigação semiestruturada. A entrevista foi realizada em única etapa, na qual o entrevistador aplicou um questionário semiestruturado aos entrevistados. Foram realizadas treze entrevistas e optou-se por anotar as respostas e não gravar as entrevistas.

Para a interpretação e estudo dos dados observados e coletados no decorrer da pesquisa empírica foram realizadas duas estratégias gerais de análise: o uso de fontes teóricas e a descrição do caso. A modalidade de análise foi baseada na 
estratégia da adequação ao padrão sugerida por Yin (2005). Dessa forma realizouse uma descrição do estudo de caso e posterior comparação dos dados coletados com os pressupostos teóricos apresentados neste trabalho.

\section{Análise dos Resultados}

\subsection{Empresa estudada}

A empresa Beta Ltda. é especializada em armazenagem de granéis líquidos, com armazéns de terminais marítimos nos EUA, Europa, China e Brasil. A empresa atua no Brasil há 28 anos e está localizada no porto de Santos com acesso imediato ao complexo Anchieta - Imigrantes e interligada aos berços de atracação de navios através de tubulações. Tem aproximadamente 75 funcionários e um faturamento anual da ordem de $\mathrm{R} \$ 60$ milhões.

A empresa fornece serviços de armazenagem de granéis líquidos, principalmente para exportação e importação, tem capacidade de 125.025 metros cúbicos distribuídos em 84 tanques de capacidades variadas. A empresa pode armazenar uma grande variedade de produtos, principalmente derivados de petróleo, alcoóis, biocombustíveis, ácidos, lubrificantes e outros produtos químicos, além de óleos e gordura vegetal ou animal. Ela opera como um hub regional para melhorar a eficiência de operações de navios e caminhões. O acesso ao píer de atracação de navios, no porto Alemoa, é feito através de 9 tubulações, sendo 3 de diâmetro de 10 polegadas construídas em aço inoxidável, 5 de diâmetro de 8 polegadas construídas em aço inoxidável e 1 de diâmetro de 8 polegadas construída em aço carbono.

A empresa tem plano de expansão de sua capacidade de armazenamento e manuseio de produtos já em andamento. Estão sendo projetadas mais duas tubulações de acesso ao píer da Alemoa, mais tanques de armazenagem, totalizando 25.000 metros cúbicos adicionais à capacidade já existente. Além disso, um sistema padronizado de manobras intensificará as operações entre tanques, navios, caminhões e vagões. O novo sistema contará, também, com o que há de mais moderno nas novas tecnologias logísticas, incluindo avançado sistema de medição de nível de produto armazenado através de telemetria, instrumentos de 
controles, tecnologia de informação e comunicação e inovação em processo de construção de tanques.

\subsection{Conceitos relacionadas à inovação}

Nas análises documentais da empresa, assim como nas entrevistas aos gestores, foi possível identificar os valores da empresa: construir uma cultura de disciplina e respeito, encorajando a diversidade e fomentando a geração de ideias criativas e inovações; nutrir um ambiente que favoreça o trabalho em equipe; conduzir os negócios de forma segura respeitando o meio ambiente e comprometidos com a boa cidadania corporativa. Como objetivos, foram identificados os seguintes: gerar resultados consistentes aos acionistas, concentrando esforços na eficiência, inovação, na gestão de riscos, controle de custos, crescimento da receita e lucros com o melhor retorno do capital investido. Portanto, tanto nos valores como nos objetivos da empresa aparece a palavra inovação.

Os gestores consultados têm ideia geral do que é inovação, de uma forma simplificada a definem como algo novo, desenvolvido e diferente do que é comum no dia a dia da organização. Entretanto, não se preocupam com as classificações das inovações, apenas as distinguem de melhorias contínuas. Quanto às melhorias contínuas, não definem com muita clareza até onde vai a melhoria contínua e se inicia a inovação. Entretanto, eles relacionam melhorias contínuas às práticas de qualidade. Segundo Roberts (2007) a inovação é composta de duas partes: a geração de uma ideia ou invenção e a conversão daquela ideia em negócio ou outra aplicação utilizável.

\subsection{Inovações recentes e questões relacionadas}

\subsubsection{Tecnologia de Informação na rede de suprimentos de etanol para exportação}

Importante informação de TI foi obtida, como veremos a seguir, no fluxo de informações na logística integrada do etanol. Na Figura 2, as linhas tracejadas indicam os fluxos de informação entre os vários atores da logística integrada do 
etanol. Devido à existência de muitos e pulverizados atores na logística integrada do etanol, verificou-se a existência de um concentrador de informações, que é dado por uma empresa conhecida no mercado como Trading. Do ponto de vista das TI, as informações trocadas entre a usina e a Trading, indicadas pelo número 1, na figura, ocorrem por meio de e-mail com planilha Excel. As informações entre as empresas de transporte, tanto aquelas de modal terrestre como a de modal aquaviário, indicadas pelos números 2, 4 e 6 , e a Trading também são trocadas por e-mail. Concomitantemente, as informações entre a empresa cliente e a Trading, indicada na figura pelo número 7 , são igualmente trocadas pelo e-mail, assim como ocorre com as informações trocadas entre a Trading e o inspetor de qualidade. Por fim, talvez, o achado mais interessante da pesquisa foi a constatação de que as informações entre o terminal de armazenagem da empresa Beta Ltda. (no porto de Santos) e a Trading são trocadas por meio de uma intranet, em que a Trading consegue acessar as informações disponibilizadas pelo sistema do terminal portuário, com informações sobre estoques e posições dos caminhões na entrada e saída do terminal. A inovação em questão foi o sistema de intranet possibilitando melhores informações e contribuindo para o fluxo mais homogêneo de envio de produto ao porto de Santos.

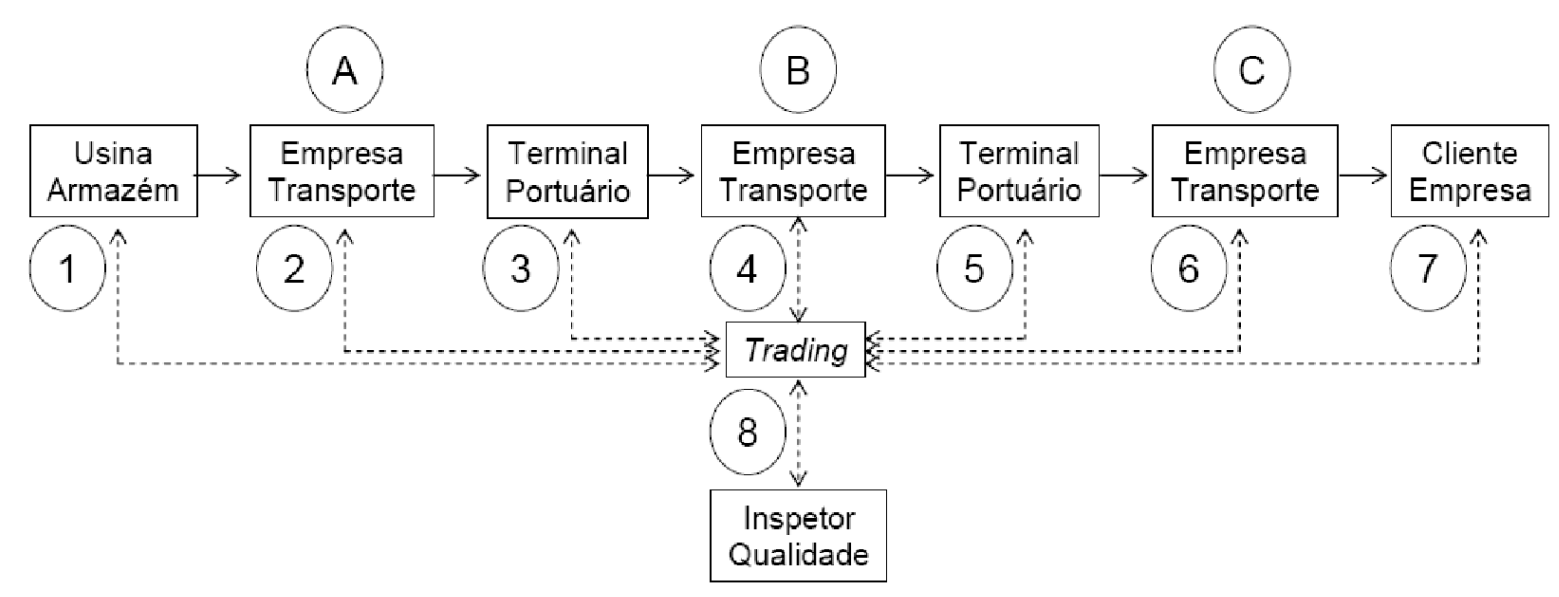

\section{Figura 2}

Modelo de fluxo de informação e mercadoria na cadeia do etanol Fonte: dados da pesquisa.

Segundo os gestores, a inovação da intranet surgiu após vários contatos com o cliente empresarial, a Trading. Portanto, o papel da interação empresa-cliente foi forte nesse processo. Eles ressaltaram a importância da qualificação técnica de seus 
colaboradores para lidar com a nova tecnologia, facilitado pelo programa de treinamento da empresa e pela qualificação técnica do grupo, não dificultando a implementação do processo. De acordo com Roberts (2007) a estrutura organizacional que alavanca inovações tecnológicas requer foco em ambos os conhecimentos, internos e externos à organização.

\subsubsection{Método de construção de tanques de armazenagem}

O processo anterior consistia em construir o tanque iniciando pela parte inferior; fundo e primeiro anel, as chapas de aço já calandradas eram soldadas fechando o primeiro anel e assim concomitantemente, até chegar ao topo do tanque. Havia a necessidade de montagem de andaimes externos e internos para acesso aos soldadores e montagem dos anéis; posteriormente, o teto pré-montado era içado e soldado no topo do tanque.

Com inovação tecnológica, as empresas especializadas em montagem de tanques, mais recentemente, passaram a utilizar o sistema de "macacos" com acionamento elétrico na montagem dos tanques. Esse processo permite a execução da tarefa de montagem do tanque no sentido inverso, quando comparado ao método tradicional.

O sentido inverso ocorre porque é possível iniciar a montagem pelo teto do tanque, no solo, instalar todos os acessórios e na sequência montar todos os anéis na ordem decrescente, ou seja, do último para o primeiro anel. Os "macacos" são estrategicamente instalados ao redor do tanque, com dispositivos apropriados, e as seções montantes são levantadas permitindo a montagem do módulo seguinte com muita segurança.

A utilização desse sistema reduz o tempo de construção em $20 \%$ quando comparado ao método tradicional, ou seja, montando o tanque de baixo para cima, com instalação de andaimes e equipamentos para içar cargas. Além da produtividade, o sistema dos equipamentos com "macacos" elétricos é mais seguros, pois $95 \%$ das atividades são executadas a uma altura máxima de 2 metros, reduzindo, consideravelmente, os riscos de acidentes. E, consequentemente, os custos são menores quando comparados ao sistema tradicional.

Os gestores da empresa ressaltaram a importância dessa inovação tecnológica na construção de tanques, haja vista que os tanques têm composição @@ Revista Gestão \& Tecnologia, Pedro Leopoldo, v. 17, n. 1, p. 277-296, jan./abr. 2017288 
importante nos custos do negócio e, com o aumento nos últimos anos do preço do aço, essa inovação foi importante para reduzir o impacto desse aumento. Eles informaram, também, que houve pouca interação de seus clientes empresariais nessa inovação. A inovação se deu mais da parte das empresas especialidades em montagem de tanques, treinamento de seus colaboradores e seus fornecedores. Segundo Jaruzelski e Dehoff (2010) a combinação de talentos, conhecimento, estrutura de time, processos - a capacidade que as empresas de sucesso põem juntas, habilitam seus esforços de inovação para criarem produtos e serviços de sucesso.

\subsubsection{Instrumentos em tanques de armazenagem}

Outras inovações tecnológicas relevantes identificadas no estudo de caso foram os instrumentos usados nos tanques de armazenamento e no sistema de movimentação de carga. Os gestores mencionaram os instrumentos de alta tecnologia para monitoramento do volume e temperatura dos produtos de granéis líquidos armazenados. No sistema anterior, de medição de tanques, havia a necessidade de inserir uma trena metálica, geralmente de aço inoxidável, através de um bocal determinado e específico, no tanque, para medir, verificando a altura da coluna de líquido no interior do tanque.

A medição do tanque manualmente, como era conhecida, tinha vários pontos de desvantagem; principalmente a exposição do operador à ação dos gases e do próprio produto, além da exposição do funcionário ao trabalho em altura. Havia também alta probabilidade de erro humano nas medições, emissão de vapores à atmosfera e riscos de explosão, devido à eletricidade estática, quando se tratava de vapores inflamáveis.

Com a inovação tecnológica, utilizando sistema de verificação do volume de produto armazenado por telemetria, todos os riscos acima mencionados foram eliminados. Além disso, é possível a verificação online do volume do tanque e da movimentação de produto. Essa informação contribuiu, também, para a implementação da inovação mencionada no item I, referente à tecnologia de informação e comunicação. 
O instrumento de telemetria de alta tecnologia verifica a altura da coluna de líquido no interior do tanque através de sinal de ondas, que são geradas e lançadas até a face do produto, retornando ao instrumento que verifica eletronicamente o comprimento da onda recebida, calculando o volume do produto estocado no interior do tanque naquele instante. Para a base dos cálculos, são imputados no programa de gerenciamento do sistema de telemetria todos os dados do tanque como, por exemplo, altura, diâmetro, além de outras informações relevantes ao processo.

Interligados ao sistema de telemetria há sensores de temperatura que fazem uma varredura do interior do tanque e transmitem o resultado da real temperatura naquele instante. Essa informação é processada pelo instrumento de telemetria que corrige o volume do produto armazenado à temperatura ambiente. Como alguns produtos são descarregados e armazenados à temperatura diferente da temperatura ambiente, essa correção é importante para o resultado exato e controle adequado dos estoques.

De acordo com o estudo de caso, a necessidade dos clientes em obter informações precisas e instantâneas, além de melhora e segurança do sistema, colaborou com a empresa para buscar soluções tecnológicas, inovando seu processo. Roberts (2007) ressalta que de 60 a 80 por cento das inovações tecnológicas de sucesso são iniciadas por atividades de respostas às necessidades de clientes. A implementação não foi de alto grau de dificuldade, assim como o treinamento dos operadores para lidar com a nova tecnologia.

\subsubsection{Variadores de frequência}

Outra inovação tecnológica importante mencionada pelos gestores foi o sistema de variadores de frequência. Eles começaram a ser utilizados em terminais de graneis líquidos para auxiliar no controle do bombeamento de produtos líquidos. Os variadores de frequência são ajustados em função do produto a ser movimentado através de bombas de deslocamento. Com a intervenção na frequência do motor é possível ajustar, na escala unitária, a velocidade do motor elétrico e consequentemente a vazão de bombeamento do líquido. Controlando a velocidade do líquido bombeado é possível gerenciar a pressão, vazão e principalmente eliminar a geração de eletricidade estática, que é o fator de maior risco na atividade de trabalho com granéis líquidos. 
Essa inovação tecnológica teve pouca participação dos clientes da empresa e mais participação de fornecedores e outros atores. De acordo com Roberts (2007), o mundo das inovações e invenções tem aberto cada vez mais suas fronteiras, integrações internas - externas têm sido atualmente um grande desafio gerencial. Quanto à implementação da inovação tecnológica, não houve grandes dificuldades e foram poucas as necessidades de treinamento dos operadores.

\subsubsection{Controle de carregamento de caminhões}

O modal de transporte rodoviário é o mais utilizado no Brasil, a eficiência no carregamento é fator preponderante em qualquer operação de carregamento de granéis líquidos. Segundo os gestores da empresa esse é o item com maior interferência dos clientes organizacionais, fomentando a geração de ideias e inovações na empresa. De acordo com Perrino e Tipping (1989), as empresas podem obter mais informações que auxiliarão em suas inovações tecnológicas através das necessidades de seus clientes.

Há vários equipamentos modernos que podem ser utilizados em terminais de granéis líquidos, reduzindo a interferência humana no processo e com isso tornandoo mais seguro e eficaz. Entre as possibilidades, a empresa adotou o uso de instrumentos automatizados para carregamentos de caminhões que são compostos por integradores eletrônicos interligados ao medidor de vazão, funcionando como um registrador de quantidade (massa ou peso), assim o sistema ao perceber a quantidade pré-registrada finaliza a operação fechando válvulas e desligando bombas, além de sinalizar a atividade concluída. O sistema foi de fácil implementação, requereu pouco treinamento dos operadores e melhorou a eficiência e eficácia do carregamento de granéis líquidos.

\subsubsection{Braços de carregamentos}

Os gestores também mencionaram como inovação tecnologia os modernos braços de carregamentos de caminhões. Os braços de carregamentos são equipamentos para carregamento de granéis líquidos pela parte superior do caminhão, permitindo flexibilidade, segurança, agilidade, facilidade de carga e 
descarga em caminhões e containers ou vagões tanques. Eles são equipados com sistema de coleta de vapores e com sistema de eliminação de energia estática.

Essa inovação tecnológica deu-se devido às diversas conversações com clientes empresariais. De acordo com Chesbrough (2003), o cliente tem informações importantes que podem ser vitais para a "inovação aberta". A empresa de "inovação aberta" convida o cliente para participar do processo de inovação. Quanto ao treinamento dos funcionários para a implementação da inovação tecnológica, os gestores lembraram que não foi de grande dificuldade.

Os principais aspectos do modelo de Hertog (2000) foram encontrados nas inovações identificadas e estão sintetizados, de acordo com os entrevistados, na Tabela 1. 
Tabela 1

Inovações tecnológicas pesquisadas

\begin{tabular}{|c|c|c|c|c|}
\hline Inovação & Descrição & $\begin{array}{l}\text { Papel da } \\
\text { interação com } \\
\text { o cliente }\end{array}$ & $\begin{array}{c}\text { Arranjo } \\
\text { organizacional }\end{array}$ & Implementação \\
\hline 1 & $\begin{array}{ll}\text { Tecnologia } & \text { de } \\
\text { informação } & \end{array}$ & 5 & 4 & 2 \\
\hline II & $\begin{array}{ll}\text { Processo } & \text { de } \\
\text { construção } & \text { de } \\
\text { tanques } & \text { de } \\
\text { armazenagem } & \end{array}$ & 2 & 2 & 2 \\
\hline III & $\begin{array}{ll}\text { Instrumentos } & \text { em } \\
\text { tanques } & \end{array}$ & 4 & 2 & 2 \\
\hline IV & $\begin{array}{l}\text { Variadores de } \\
\text { frequência }\end{array}$ & 1 & 1 & 1 \\
\hline V & $\begin{array}{ll}\text { Controle } & \text { de } \\
\text { carregamento } & \text { de } \\
\text { caminhões } & \end{array}$ & 5 & 2 & 1 \\
\hline VI & $\begin{array}{ll}\text { Braços } & \text { de } \\
\text { carregamento }\end{array}$ & 5 & 2 & 1 \\
\hline Total & & 22 & 13 & 9 \\
\hline
\end{tabular}

Fonte: dados da pesquisa.

Contatou-se na pesquisa relevante participação dos clientes empresariais no processo de geração de inovação tecnológica, obtendo 22 pontos num máximo de 30 pontos. O arranjo organizacional e, principalmente, a implementação das inovações não foram de grande dificuldade, segundo os gestores, devido à boa capacitação técnica dos funcionários da Empresa Beta Ltda.

\section{Considerações Finais}

$\mathrm{Na}$ pesquisa, constatou-se que há boa noção do que é inovação para a empresa. Portanto, compactua-se com os conceitos de inovação de Meyers e Tucker (1989), que definem inovação como sendo uma ideia, prática, ou artefato percebido para ser novo por relevante adaptação.

Os gestores ressaltaram a importância das mudanças tecnológicas e da interação com os clientes organizacionais no processo de geração de inovação, reforçando os conceitos principais do modelo proposto por Hertog (2000). Em seu modelo o autor ressalta que qualquer inovação em serviços envolve alguma combinação das quatro dimensões (conceito de serviço, interface com o cliente, distribuição do novo serviço e opções tecnológicas) e pode ser a combinação delas 
que caracteriza cada inovação em serviço particular. O peso de cada dimensão e a importância das várias ligações entre elas varia de acordo com serviços individuais, empresas e inovações.

Segundo os gestores da Beta Ltda., não há, basicamente, uma formalização de encontros com o objetivo específico de geração de ideias, os encontros ocorrem naturalmente, em visitas a clientes e fornecedores, eventos como feiras e congressos. Os contatos envolvem diversos níveis hierárquicos da organização, principalmente o gerente de Marketing.

O trabalho em conjunto é facilitado pela experiência da equipe, que é composta por profissionais com conhecimento em diversas áreas dos componentes logísticos. Essa característica justifica a facilidade encontrada na pesquisa para o arranjo organizacional e a implementação das inovações, tópicos esses componentes da dimensão 3 do modelo de Hertog (2000). O que dificulta o trabalho em conjunto, segundo os gestores da empresa, é o pouco tempo disponível para maior integração com as empresas componentes do processo logístico.

Os gestores relataram, também, que utilizam o benchmarking com outras empresas, incrementando a geração de ideias inovadoras. $E$ as inovações têm gerado impactos diretos na melhoria operacional, com redução de custo, satisfação dos clientes e aumento da lucratividade.

É interessante observar que no segundo caso de inovação mencionado pela empresa (processo de construção de tanques de armazenagem) e no quarto (variadores de frequência) o papel da interação com o cliente foi de pouca intensidade. Entretanto, essas inovações surgiram dos fornecedores que relataram suas interações com diversos atores de suas redes de suprimentos. Portanto, constatamos nesses dois exemplos que, embora tenha sido possível encontrar os fatores relacionados por Hertog (2000), dimensão 2 - interface cliente novo, as interações geradoras de inovações não ocorreram numa interação simples de dualidade e sim numa interação concomitante de diversos atores de outras redes. Roberts (2007) ressalta que inovação e invenção têm que ser gerenciadas através de organizações e não apenas internamente a elas, assim como globalmente. Segundo Nambisan e Sawhney (2011), as empresas podem ampliar suas iniciativas de inovações com a colaboração externa centrada em redes.

Se analisados os resultados sob a ótica do modelo de Hertog (2000) ressaltamos o fato das inovações ocorrerem, também, num processo de interação @()@ Revista Gestão \& Tecnologia, Pedro Leopoldo, v. 17, n. 1, p. 277-296, jan./abr. 2017294 
concomitante de vários atores, ou seja, em redes, além do processo de dualidade na interface cliente novo. Portanto, para melhor entendimento do fenômeno da inovação tecnológica em serviços logísticos, poderíamos sugerir no modelo de Hertog a inclusão das redes, com diversos atores contribuindo com o processo de geração de inovação. Entretanto, devemos lembrar que há limitações no estudo em função de pesquisarmos apenas uma empresa, por se tratar de estudo de caso. Fica em aberto um campo de pesquisas para outros estudiosos.

\section{Referências}

Chesbrough, H. (2003) Open innovation: the new imperative for creating and profiting from technology. Harvard Business School Press: Boston.

Ciampi, Melany M. et al. (2016). Science, engineering, and technology innovation for global human challenges. ASEE's 123rd Annual Conference \& Exposition. Recuperado de <https://repositorium.sdum.uminho.pt/handle/1822/42189>

Collis, J., \& Hussey, R. (2005). Pesquisa em Administração. Bookman: Porto Alegre.

Drucker, P. F. (2011). Inovação e espírito empreendedor (entrepreneurship): prática e princípios. São Paulo: Cengage Learning.

Eisenhardt, K. (1989). Building Theories from Case Study Research. Academy of Management Review, 14(4), 532-550.

Hagedoorn, J., Lokshin, B., \& Malo, S. (2016). Alliances and the innovation performance of corporate and public research spin-off firms. Research Memorandum, 41(16), 1-42.

Hartline, M. D., \& Ferrell, O. C. (1996). The management of customer-contact service employees: an empirical investigation. Journal of Marketing, 60(4), 52-70.

Hertog, P. D., GallouJ, F., \& Segers, J. (2011). Measuring innovation in a "low-tech" service industry: the case of the Dutch hospitality industry. The Service Industries Journal, 31(9), 1429-1449.

Hertog, P. D., \& de Jong, G. (2007). Randstad's business model of innovation: Results from an exploratory study in the temporary staffing industry. Innovation: Management, Policy \& Practice, 9(3-4), 351-364.

Hertog, P. D. (2000). Knowledge-intensive business services as co-producers of innovation. International Journal of Innovation Management, 4(4), 491 - 528.

Huang, C. Y., Tzeng, G. H., \& HO, W. R. J. (2011). System on chip design service ebusiness value maximization through a novel MCDM framework. Expert Systems with Applications, 38(7), 7947-7962. 
Jaruzelski, B., \& Dehoff, K. (2010). The global innovation 1000: how the top innovators keep winning. Stategy+Business magazine. Disponível em https://www.strategy-business.com/article/10408?gko=08375

Lamb, C. W., Hair, J. H., \& McDaniel, C. (2008). Segmenting and Targeting Markets. Chapter 8. Marketing. 10th ed. New Jersey: Cengage Learning.

Lopes, A. P. V. B. V. et al. (2016). Innovation management: a systematic literature analysis of the innovation management evolution. Brazilian Journal of Operations \& Production Management, 13(1), 16- 20.

Meyers, P. W., \& Tucker, F. G. (1989). Defining roles for logistics during routine and radical innovation. Journal of the Academy of Marketing Science, 1, 73-82.

Nambisan, S., Sawhney, M. (2011). Cérebro Global: como inovar em um mundo conectado por redes. São Paulo: Évora.

Orlikowski, W. J., \& Baroudi, J. J. (1991). Studying information technology in organizations: Research approaches and assumptions. Information Systems Research, 2(1), 1-28.

Perrino, A. C., \& Tipping, J. W. (1989). Global Management of Technology: an approach to formulating an R\&D deployment strategy for a global technology network emerges from a study of 16 multinationals in the U.S., Europe and Japan. Research Technology Management 32(3), 12-19.

Remeneyi, D., Money, A., Price, D., \& Bannister, F. (2002). The creation of knowledge through case study research. Irish Journal of Management, 23(2), 1-17.

Roberts, E. B. (2007). Managing invention and innovation. Industrial Research Institute. Inc., 35-54.

Rubalcaba, L., Gallego, J., \& Hertog, P. D. (2010). The case of market and system failures in services innovation. The Service Industries Journal, 30(4), 549 - 566.

Stake, R. (1995). The art of case research. Thousand Oaks, CA: Sage.

Triviños, A. (1987). Introdução à pesquisa em ciências sociais: A pesquisa qualitativa em educação. São Paulo: Atlas.

Yin, R. K. (2005). Estudo de Caso: Planejamento e Métodos (3a ed.). Porto Alegre: Bookman.

Zhu, F., \& Godes, D. (2009). Impact of online consumer reviews on sales: The Moderating Role of Product and Consumer Characteristics. Journal of Marketing, 74(2), 133-148. 